\title{
Policy on Water Loss Control in China
}

\author{
Xinyue Liu, Shihu Shu \\ National Engineering Research Center of Urban Water Resource, Shanghai, China \\ Email: liu.x.yue@hotmail.com
}

How to cite this paper: Liu, X.Y. and Shu, S.H. (2018) Policy on Water Loss Control in China. Journal of Geoscience and Environment Protection, 6, 100-107. https://doi.org/10.4236/gep.2018.63009

Received: January 31, 2018

Accepted: April 5, 2018

Published: April 8, 2018

\begin{abstract}
The Chinese government has raised great attention on water resources and environment over the past several years. In dealing with the issues of water pollution, water management, and the imbalance of water resources, China's state council released "Water Pollution Prevention and Control Action Plan" in 2015. This policy has become a guideline to promote water sustainability in the long run. Since then, a number of regulatory policies were released to increase the focus on water conservation. Among those actions, water loss control associated with distribution systems is regarded as a key solution to improve water supply efficiency. This paper provided a comprehensive introduction to the framework of water loss control policy in China.
\end{abstract}

\section{Keywords}

Water Distribution Networks, Water Loss Control, Water Ten Plan, Water Loss Rate, Non-Revenue Water Rate

\section{Introduction}

The water distribution network, delivering treated drinking water from water plants to consumers, is a critical part of water supply industry. With the development of economy along with the growing populations, the water demands have been significantly increased. Accordingly, the existing water distribution networks have encountered numerous challenges. Leakage in water distribution networks has been a common problem faced by water utilities worldwide, along with adverse effects on the economy, environment and society, which led to the need for innovative strategies to control water losses and better performance level of water distribution networks. Effective water loss control benefits not only water utilities but also the whole community. For water utilities, water loss control results in reducing non-revenue water and maximizing water supply efficiency. For the community, it can better sustain water resources, and improve the stability and safety of water consumption. Therefore, the regulations, policies 
and practices promoted and enforced by the government and water utilities have been emphasizing on water loss control.

\section{The Current Status of Water Losses in China}

In China, two percentage indicators are utilized for assessing water losses in distribution systems, as well as the water supply services of water utilities: water loss rate and non-revenue water rate [1].

According to the "standard for water loss control and assessment of urban water distribution system" (CJJ92-2016) [2] issued by Ministry of Housing and Urban-Rural Development, the term "water loss" is defined as the difference between system input volume and authorized consumption, which consist of real losses (or physical losses), that include water loss from the system as leakage, and apparent losses (such as metering inaccuracies and data errors) and other losses (such as unauthorized consumption), which is slightly different from AWWA Water Balance for there is an extra category for "other losses". Hence, "water loss rate" is defined as the amount of water losses over system input volume. The other term "non-revenue water" includes the amount of water lost from water distribution systems and the unbilled volumes associated with lost revenue from water supplied, plus the authorized unbilled consumption. And "non-revenue water rate" is the amount of non-revenue water over system input volume. Calculations are as follows:

$\%$ Water Loss Rate $=($ Water Losses $) /($ System Input Volume $) \times 100 \%$

$\%$ Nonrevenue Water Rate $=($ Nonrevenue Water $) /($ System Input Volume $) \times 100 \%$

The China Urban Water Association (CUWA) releases the "Urban Water Supply Statistical Yearbook" every year, publishing the data collected from the previous year. According to "Urban Water Supply Statistical Yearbook 2016" [3], the national average water loss rate of 2015 is $14.32 \%$. It has been decreased by 1 percentage point compared to 2014. It is supposed to be reduced lower than $12 \%$ by 2017 as required in "Water Ten Plan". The data for major provinces, autonomous regions and municipalities are shown in Figure 1.

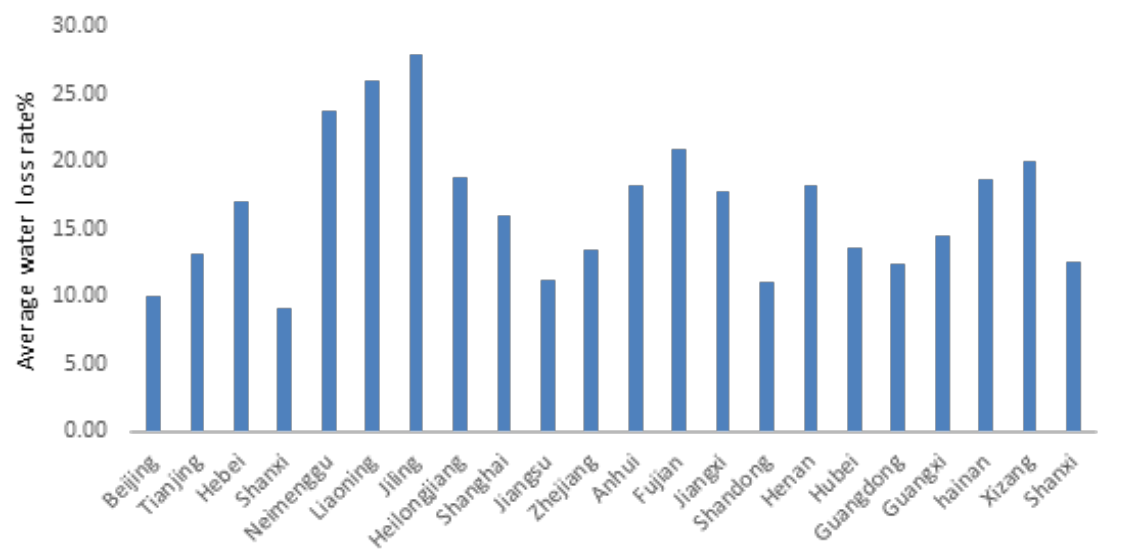

Figure 1. Water loss rates from major provinces in 2015. 


\section{International Water Loss Control Policies}

In 1994, the report "Managing Water Losses", published by United Kingdom Water Industry Research (UKWIR), including presentation of consistent and systematic methodologies that allowed the understanding, measurement and reduction of losses in distribution networks. These reports have marked a change in attitude on the part of the water supply industry, progressively guiding actions toward management of systems losses. The emphasis currently observed as regards this issue, results in the consequent development of a large number of research activities, whilst a major concern is primarily on the ability of managing utilities to measure and evaluate the performance levels of their water distribution networks.

In 2001, the American Water Works Association (AWWA) conducted a comprehensive survey of the extent of accounting and loss control policies existing in the US [4]. The survey showed the structures in place are cursory and could not validate the performance of water utilities. Over the past several years, the International Water Association (IWA) and AWWA have emphasizing on the quantitative management of water resources, the Water Loss Task Force (WLTF), was formed in 2003, which is aimed to reducing water losses with practical approaches. The WLTF developed the water audit methodology, which was quickly embraced by AWWA's Water Loss Control Committee (WLCC) and was embodied in the AWWA guidance manual M36, Water Audits and Leak Detection, the 4th edition entitled Water Audits and Loss Control Programs was released last year [5].

Given the increasing awareness of water resource conservation, "A Blueprint to safeguard Europe's water resources" [6] was published in 2012 by the European Commission. This is a matrix designed to preserve water resources in Europe, aimed mainly at the problem of leakage in water distribution networks. The Commission states that "these issues should be addressed to assess the environmental and economic benefits of reducing their levels of losses. The situation is very different between member states, where between them, the rates of water losses vary between $7 \%$ and $50 \%$ or even more. The Commission will work with the European water industry to accelerate the development and dissemination of best practices with regard to economically sustainable levels of leakage. The proposed action consists in a matrix defined in the publication to be made by the Commission, Member States and the water sector, covering best practices and tools to achieve a sustainable economic level of leakage.

\section{Current Regulatory Trends}

\subsection{Water Pollution Prevention and Control Action Plan}

In April 2015, "Water Pollution Prevention and Control Action Plan" was released by the State Council, also known as "Water Ten Plan". Including National Development and Reform Commission, Ministry of Housing \& Urban-Rural Development, Ministry of Water Resources and other departments, a total of 12 
ministries and government departments have jointly prepared the action plan for 2 years since 2013. It was promulgated as an extension of the new environmental protection law of China. It is an integrated plan that consists of $10 \mathrm{sec}-$ tions with 35 provisions, including 238 specific measures in total, attempt to address urgent water-related issues and set long-term goals. It served as the guideline to promote water sustainability in the long run. This is probably the most comprehensive water policy to date. In addition, the action plan was followed by the "Implementation Regulations for Water Pollution Action Plan (Tentative)" for evaluating the actual performances of provinces, autonomous regions and municipalities.

Water Ten Plan proposed measures and set out long-term objectives at the national level. On one hand, it initiated the movement of renovating and upgrading aging water pipes in distribution networks that have been in service for more than 50 years and made of outdated materials. On the other hand, it set the long-term goal for the national average leakage rate in water distribution networks, which should be keep lower than $12 \%$ by 2017 , and be further reduced to $10 \%$ by 2020 . Additionally, water deficient prefecture-level cities and above should meet the requirements of national water-saving cities standards. It also mentioned that regions such as Beijing-Tianjin-Hebei area, Yangtze River Delta and Pearl River Delta should achieve the goal one year ahead of schedule [7].

\subsection{National Water Conservation Plan}

In October 2016, National Development and Reform Commission, Ministry of Water Resources, Ministry of Housing and Urban-Rural Development and other nine ministries jointly issued the "National Water Conservation Plan", which proposed to improve water use efficiency through all industries. It called for public awareness and participation in water conservation actions [8].

Key requirements are as follows:

1) Scientifically develop and implement technical renovation plan for water distribution networks.

2) Promote the development of leakage detection and localization system.

3) Strengthen the supervision and management of water distribution network operations.

Specifically, by 2020 , it required to implementation of district metered areas (DMAs) in 100 cities, and the renovation of about 70,000 km of distribution system should be completed. Water-stressed cities such as Beijing and Tianjing were required to take the lead in implementing district metered areas (DMAs).

\subsection{Guideline of Urban Water Conservation Action}

In order to promote the water-related decision made by the Central Party Committee and the State Council, a guideline on urban water conservation action has been released in November 2016 jointly by Ministry of Housing and Urban-Rural Development and National Development and Reform Commission to 
guide in deepening water-saving work in urban areas.

The guideline pointed out that water loss control has become the focus of urban water conservation. Three approached were presented in the guideline. First, upgrade aging water distribution systems. Second, promote the construction of DMAs system and complete the corresponding reconstruction project of the pipe networks, pump station, and installation of the partition valves and metering equipment in the district areas. Third, gradually upgrade those facilities in residential areas that cannot meet the requirements [9].

\section{4. "13th Five-Year Plan" for Water-Saving Society Construction}

In January 2017, National Development and Reform Commission, Ministry of Housing and Urban-Rural Development, Ministry of Water Resources jointly issued “13th Five-year Plan' for Water-saving Society Construction”. It called for reconstruction of urban water distribution networks, accelerate the renovation of distribution networks that are damaged, made of outdated materials and have been in service for more than 50 years, for reducing water losses and occurrences of pipe bursting. By 2020, the national average leakage rate in public water distribution networks should be controlled under $10 \%$. In addition, it required to improve leak detection and management in water distribution networks by implementing approaches such as district metering areas (DMAs) and water balance test, and conducted DMAs management demonstration projects in cities with severe leakage situation and cities that were water-stressed [10].

\section{Implementation and Management of DMAs in Distribution Networks}

Given the regulations and policies discussed above, it is clear that district management has become the mainstream water loss control strategy. It is necessary to put the concept of "district planning" throughout the entire process including network planning, design, construction, maintenance and operation. District metered areas (DMAs) is one of the advanced technologies and management tools to improve water supply network leakage control efficiency. With the construction of DMAs system, leaks can be effectively identified in distribution systems based on water balance test. As a result, it can better guide leakage control and improve water loss management.

Early in 2017, Ministry of Housing and Urban-Rural Development released the "Guideline of Management of DMAs in Urban Water Distribution Networks", for the purpose of taking systematic idea throughout urban water distribution networks leakage control, with an emphasis on application of district metered areas, and finally attain the goal of "Water Ten Plan" [11].

The guideline provided regulatory support for implementation of DMAs. The basic idea of DMAs management is to build a multiple-level system for achieving different levels of metering and develop an DMAs management platform based on distribution network GIS system. The platform should strengthen the data 
fusion with other management systems such as water dispatching, charging, and secondary water supply facilities management.

Urban water supply departments determine the targets of district metered areas management, and coordinate with water utilities and other relevant departments to provide guarantee for implementation of DMAs. Meanwhile, supervise and assess the operation of DMAs, including water quality and pressure in accordance with the national standards (GB5749, GB50788, etc.). The DMAs management process is described in Figure 2.

\section{A Vision of Broad Recognition for Water Loss Control}

For water utilities, it is important to get a whole picture of their properties and track the distribution system they manage. On one hand, scientifically upgrade and reconstruct aging infrastructures and distribution systems. On the other hand, implement district metering as the front line to control losses proactively in distribution systems, and develop the management platform for knowing the real-time operation status, and precisely localizing leaks and bursts in order to make responses as soon as possible.

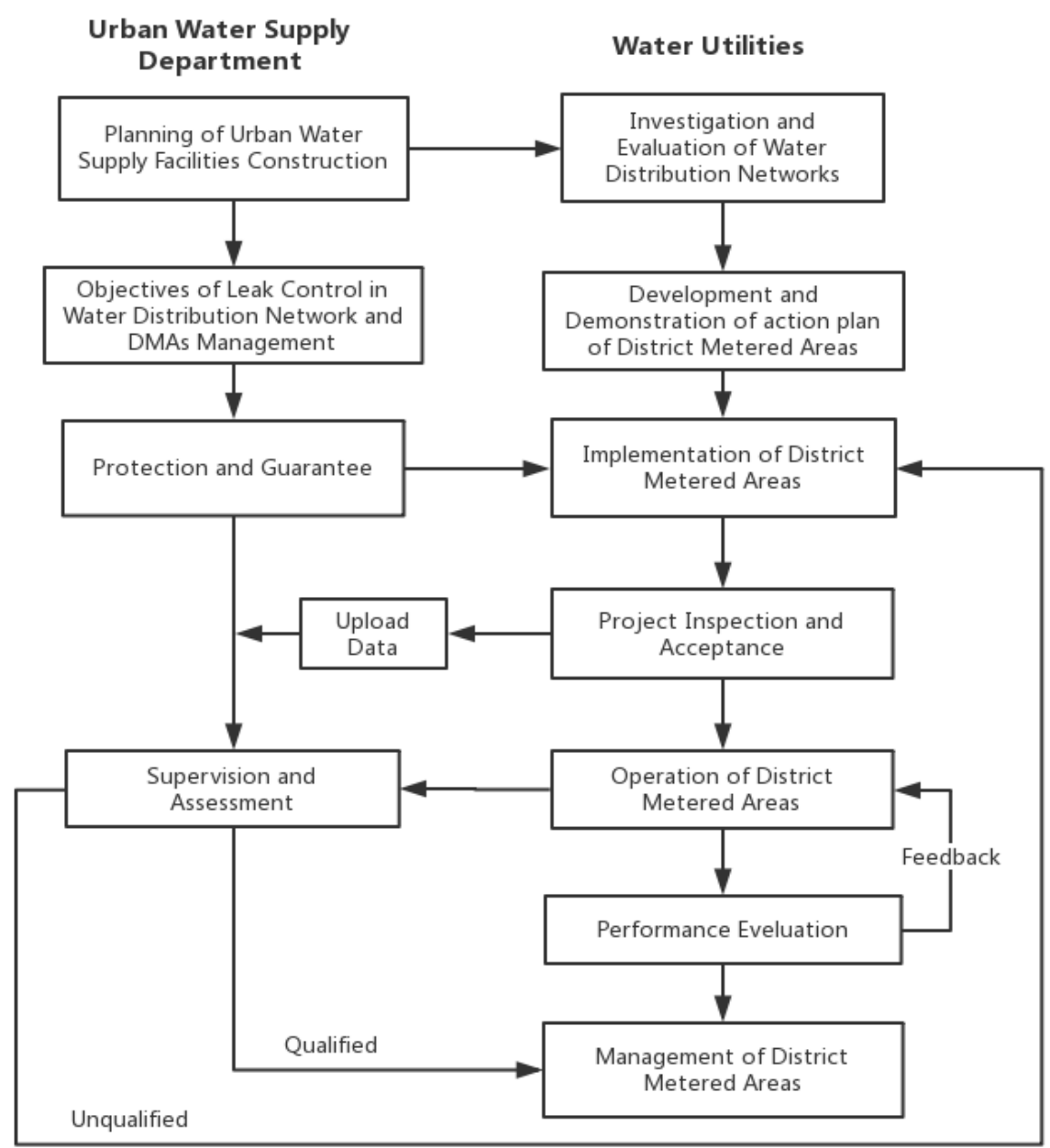

Figure 2. DMA management flow chart. 
Moreover, existing regulatory actions are mainly promoted from a macro-level prospective rather than a local perspective. Accordingly, in order to effectively reduce water losses in the long run, local governments could draw up their own action plans with adjusted goals to local conditions, and adjusted plans as needed.

\section{Conclusions}

Due to the complexity of causes and contributing factors of leakage in water distribution networks, water loss continued as a major problem that concerned by water utilities. Water utilities have put active efforts on water loss control in years, however, they mainly focus on water loss management practices with limited investment, and the result is not satisfactory. At present, the water loss level in China is about the average among the world, and the mission of minimizing water losses is still tough. Fortunately, many policies and practices promoted at the national level by the government have been emphasizing on water loss control. Policies and regulations discussed in this paper drew up the outline for controlling water losses, clarified the responsibilities, and set out long-term objectives. With these progressive movements, both rates of water losses and non-revenue water have been decreasing.

Policies and regulations detailed above have provided regulatory support and better guidance for water loss control program and practices in China, and also called for involvement of the governing body, water utilities and social forces. Further collaborations both from technical standpoint or a legal framework are needed for combating water losses associated with distribution networks in an efficient and economical way.

\section{References}

[1] Shu, S.H. (2015). Example of Correction Calculation for Distribution Loss Rate of Regional Water Supply Based on Partition Metering (in Chinese). Journal of Water Technology, 9, 42-44.

[2] Ministry of Housing and Urban-Rural Development (2016) Standard for Water Loss Control and Assessment of Urban Water Distribution System (CJJ92-2016).

[3] Urban Water Supply Statistical Yearbook (2016) China Urban Water Association (CUWA)

[4] Kunkel, G. (2005) Developments in Water Loss Control Policy and Regulation in the United States. In Proc. of the Leakage 2005 Conference.

[5] American Water Works Association (2016) Manual of Water Supply Practices M36, Water Audits and Loss Control Programs, 4th Edition.

[6] European Commission (2014) A blueprint to Safeguard Europe's Water Resources. Brussels, Belgium.

[7] The State Council (2015) Water Pollution Prevention and Control Action Plan.

[8] National Development and Reform Commission (2016) National Water Conservation Plan.

[9] Ministry of Housing and Urban-Rural Development (2016) Guideline of Urban 
Water Conservation Action.

[10] National Development and Reform Commission (2017) "13th Five-year Plan" for Water-saving Society Construction

[11] Ministry of Housing and Urban-Rural Development of the People's Republic of China (2017) Guideline of Management of DMAs in Urban Water Distribution Networks. 